\title{
Will new guidelines protect or expose the Indian gene pool?
}

Only four months after the introduction of new guidelines for the use of tissue samples and genetic information, some observers are questioning whether the new regulations, designed to protect Indian citizens, are in fact making their exploitation easier.

Since February 1998, the only requirement for researchers from government or independent laboratories to export Indian tissue samples to foreign collaborators is the permission of an internal Institutional Review Board (IRB) and notification to the Indian Council of Medical Research (ICMR). Prior to this time ICMR authorization was mandatory. This means that the ICMR no longer has the power to veto exports and its role has become one of a secretariat maintaining a record of all collaborative projects.

Although the guidelines still call for commercial laboratories and universities to seek ICMR permission, many are believed to be preparing to manipulate the system by including a government or institute laboratory as a third partner in their program in order to pass samples through their IRB's.

Ranjit Roychoudhury, emeritus professor at the National Institute of Immunology in New Delhi, who was involved in drafting the guidelines, denies that they have made it easier for foreign companies to access Indian genetic data. He points out that foreign researchers must now sign a material transfer agreement to protect the rights of Indian study subjects. This agreement, Roychoudhury says, deals with controversial issues such as intellectual property rights, patents applications, publication rights and arrangements for future commercial exploitation. The legal strength of such a document remains to be tested.

A demonstration that India is becoming conscious of the commercial and clinical value of its gene pool is the establishment National Facility for Functional Genomics (NFFG) in New Delhi. NFFG chief, Samir Brahmachari, says the aim of the facility is to discover novel disease genes using biological samples readily available from the nation's hospitals that are being networked with NFFG. The Department of Biotechnology has pledged to invest $\$ 25$ million in NFFG and human genomics research over next five years.

"Several cases of rare genetic disorders are likely to be found merely because of India's distinctive population," says Brahamachari. The preponderance of co-sanguine marriages, limited geographical movement of families over several generations and large family size adds to the value of the gene pool in terms of genetic research.

But some are wary of India's genetic revolution. Geneticist Suman Sahai feels that the speed with which the country is entering into the field of genetic research will raise a multitude of ethical questions that have been the subject of years of debate in more scientifically advanced countries, but which India has not had time to prepare for. K.S. JAYARaman, NeW Delhi

\section{Superior Electrophoresis Products}

\author{
Novel Pre-Cast Gels \\ Excellent Nucleic Acid Resolution \\ - High Throughput \\ - Novel Matrices/Patented Technology \\ - Easy to Use \\ Pre-Cast Gels Ideal for: \\ - Microsatellite Analysis \\ - RFLP/RAPD \\ - Mutation Detection/Heteroduplex Analysis \\ - DNA Fragment Recovery \\ - Oligo Purity Verification \\ Total Systems Available \\ - Advanced Electrophoresis Apparatus \\ - Power Supplies and Accessories
}

\section{Advanced Matrices for Sequencing Applications}

PAGE-PLUS ${ }^{\text {TM }}$ Patented Technology

- Optimized Formulations for Most Sequencing Platforms

Stable Liquid Acrylamide Products

- Optimized Ratios and Concentrations

- Unique Delivery System

Buffers for Electrophoresis Applications

- Multiple Forms such as Easy TBE ${ }^{\mathrm{TM}}$ Tablets

- Concentrated Forms and Pouches

- Optimized for Your Electrophoresis Applications

Licensed To AMRESCO Inc. from Guest Elchrom Scientific AC.

\section{aMresco}

30175 Solon Industrial Parkway, Solon, ОH 44139 USA

TEL: (800) 829-2805 FAX: (440) 349-I I 82

E-mail: amresco@worldnet.att.net URL: www.amresco-inc.com

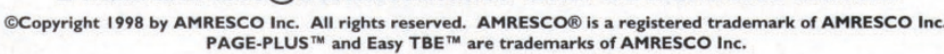

